\title{
DE ZWANENZANG VAN PAUS PIUS II (AENEAS SYLVIUS),
}

DOOR

W. MAILINCKRODT.

Het $z \ddot{j}$ mï vergund eerst dien zwanenzang van Paus Pius den tweeden op te geven, en daarna te zeggen hoe ik er aan gekomen ben. Zoo zal ik terens historie en bibliographie geven. Dit vers is van het hoogste belang voor den Maria-dienst in de $15^{\text {de }}$ eeuw, en ik vond het nergens in de werken daarover vermeld; $60 \mathrm{k}$ niet de editie van Pius' geschiedkundige, novellistische werken en brieven, waaruit ik de copie van het volgende vers nam.

${ }_{n}$ Virgo! Teutonicis multum celebrata sacellis, Mater et ipsa Dei, mater et ipsa hominis, Virgo, Latinorum spes et tutela meorum, Virgo, quam multo Gallia thure colit, Virgo, nec Hispanas paulum laudata per urbes, Cui patet et coelum totaque terra patet, Virgo, quae magnum potes exorare Tonantem, Et potes iram coelestis sistere Dei, Ipse ego, peccati servus, scelerisque minister, Et mandatorum fractor ubique decem, Ad te confugio, fateor, mortalia septem Saepius admisi crimina; aunc poenitet. VII. 
Ille licet nulli veniam negat Auctor Olympi, Et reduci semper brachia tendit amans, Quis tamen Offensi vultum, quis Judicis audet Intercessoris nudus adire sui? Ergo meos, genitrix, semper miserata labores, Nunc etiam nostris casibus affer opem. Ipse mihi de te natus sine crimine culpas Condonet veteres, prohibeatque novas!"

Ik vertaalde dit gebed tot Maria op de volgende wijze:

0 , maagd! Zoo hoog verheerlïkt en gevierd

In 't Duitsche land in tal van heiligdommen!

Gij, die in één persoon de moeder Gods,

De beil'ge moeder ook des menschen zït, 0 , maagd! De hoop en de beschermster van 't Latïnsche volk, dat mij zoo dierbaar is! 0 , maagd! Aan wie het Gallisch volk zijn wierook In tal van offers wijdt, die ook zoo luid Geprezen wordt in Spanje's schoone steden, Voor wie de bemel en geheel deze aarde Als openligt, gï, die den grooten Dond'raar Verbidden kunt, den heilgen toorn kunt stillen Door uwe voorbeê van den God des hemels, Tot u neem ik mïn toevlucht, ik, een slaaf, Der zonde! Ik een dienaar van de boosheid Ik, schuldig tegenover al de tien Geboden, die 'k zoo vaak verbroken heb! Tot $U$ neem ik mijn toevlucht. Ik erken, Dat ik de zeven doodelijke zonden Te raak begaan heb, dat ik nu daarover Berouw gevoel in 't diepste van mijn ziel! 0 , moge 't waar zijn dat Olj̈mpus Schepper Aan niemand zijn genaderïk vergeven Blijft weig'ren, dat $\mathrm{Hij} \mathrm{den} \mathrm{verloorne,} \mathrm{die}$ Terugkeert op zijn pad, met heilge liefde 
Z̈̈ne armen opent; ... maar... welk zondaar durft Zich voor 't gelaat des hoogen, heilgen Rechters, Dien hij zoo valk beleedigd heeft, vertoonen, Als hï geen Midd'laar heeft, die voor hem bidt? O, Moeder! Die barmhartig medelïden Wel steeds gevoeld hebt, met mijn nood en strïd, Met mïne ellenden. Breng mij hulp nu toe! Moog $\mathrm{Hij}$, de zonder schuld uit u geboorne, Mïn oude schuld en zonde mï vergeven, Verhind'ren dat in nieuwe ik weêr vervalle.

Wel een merkwaardig gedicht, met zijne vermenging van Christelijke en humanistisch-heidensche uitdrukkingen, eene eigenaardigheid, die wij ook vooral in het novellistische werk van Aeneas Sylvius vinden. God wordt de "magnus tonans" en de "auctor Olympi" genoemd; maar daar tegenover staan tal van uitdrukkingen uit Roomsche denk- en gevoel-wijze roortgerloeid, is Maria de middelares tusschen den zondaar en haar zoon, en wordt zij genoemd met den naam van "moeder Gods", „Mater et ipsa Dei, mater et ipsa hominis".

Dat wij hier met een gedicht te doen hebben uit de laatste dagen van paus Pius den tweeden is duidelijk. In de oude uitgave van de werken van dien paus, waarover ik ga spreken, staat het achter diens brieven, en het nummer loopt voort. Wï lezen daar toch:

Conclusio epistolarum metrico carmine de laudibus beatae Mariae virginis, Jesu Cristi gerulae.

\section{CCCCXXXII.}

$\mathrm{Ja}$, die uitgave is eene zeer belangrijke, zooals blijken zal uit de voorrede, die ik later zal overnemen. De „RealEncyclopedie für Protestantische Theologie und Kirche" van Herzog, Plitt en Hauck kent haar niet; (Zie Deel VII, blz. 18, 2de uitgare). B̈̈na een incunabel, zoo zou men de uitgare van de brieven, die ik hier bespreek kunnen 
noemen. Ik rond die in bet Historisch Archief, of de Bibliotheek der gemeente Maastricht. Het was daarin opgenomen, waarschijnlijk in de dagen der groote revolutie, toen stad en staat zooveel kloosterbezittingen eigenden. Immers voor in het boek staat nog het zeer duidelijke inschrift: „Ex bibliotheca Montis Lucis" (Tichtenberg). Dat is het vroegere klooster bij Maastricht, waar tegenwoordig de societeit Slavante is gelegen, op den Pietersberg.

Men is overeengekomen elk boek, dat niet meer in de 15de eeuw uitkwam, niet meer tot de incunabelen der boekdrukkunst te rekenen; maar het boek, waarover ik nu schrijf, verkeert in een zeer bijzonder geval. Verschenen is het toch eerst op den 8sten November 1505 bij den boekverkooper Stephanus Gueynard te Lyon in de Rue Merchière, près de St. Antoine, door de goede zorgen van Ambrosius, Archintus patricius te Milaan, en Johannes de Vingle, een geleerd drukker te Lyon. Maar de voorrede van Ambrosius is gedateerd 28 October 1496. Het drukken van het boek, dat de brieven, en daarbij nog verschillende verhandelingen en geschriften van Pius $\Pi$ bevat, schijnt dus nog al lang geduurd te hebben. Feitelijk schijnt men daarmede reeds in de $15^{\text {de }}$ eeuw bezig geweest te zijn; en desnoods kan onze uitgave dus nog tot de incunabelen gerekend worden. De aard van den druk stemt daarmede geheel orereen. De drukletter van het boek is Gothisch; en de veelvuldige af kortingen der woorden, terwïl ook soms bïzondere teekens voor samenvoegingen van letters, ja in meer bekende woorden voor geheele lettergrepen worden gebruikt, zijn oorzaak dat men zich eerst wat aan deze drukmanieren moet gewennen om ongehinderd te kunnen voortlezen. Het boek, welks papier nog sterk en uitstekend bewaard is, al is meer dan 400 jaren oud, houdt wat den vorm aangaat het midden tusschen groot octavo en kwarto. Het heeft een band van keurig geperst leder, en koperen sloten, die echter door den tand des tijds geleden hebben. Op de eene zijde van den band staat eene "rosa virtutis", op artistieke wijze in het geperste leder afgedrukt. Op een lint, dat de „rosa virtutis” omgeeft, en 
dat door engelen wordt vastgehouden, staat het navolgende opschrift:

"Haec rosa virtutis de coelo missa sereno

Eternum florens extrema sceptra geret".

Zon, maan en sterren vertoonen zich daarbij aan den hemel. Op de andere zijde van den band staat een zeer uitgewerkt wapen in het leder geperst.

Het opschrift op het titelblad der editie, in rooden inkt gedrukt, luidt als volgt:

"Epistolae et varii tractatus Pii Secundi, pontificis maximi ad diversos, in quadruplici vitae ejus statu transmissae, noviter impressae, feliciter incipiunt". Daarna in zwarten inkt en kleinere letter: „Venumdantur Lugduni ab Stephano Gueynard, ejusdem civitatis bibliopola et cive, in vico mercuriali, vulgariter, en la rue merchière, prope sanctum Anthonium". De kunstig bewerkte beginletter stelt een drukkerij en boekenzaak voor. Voordat het afdrukken der brieven, na de voorrede van Ambrosius begint lezen wij nog deze captatio benerolentiae:

${ }_{n}$ Epistolae doctissimi Aenei Silvii Senensis, quas ad amicos, dum in minoribus ageret, ex tempore exarabat, quibus etiam annexae sunt epistolae graviori stylo conscriptae, dum esset in pontificatu maximo constitutus, Pius postea nominatus. Legat et perlegat eas quisquis avidissime, quia plurimum succi continent". Aan het einde van het geheele drukwerk lezen wij het navolgende onderschrift: „Pii II, pontificis maximi, cui, aute summum episcopatum, primum quidem imperiali secretario, deinde cardinali Senensi, Eneas Sylvius nomen erat, familiares epistolae ad diversos, in quadruplici vitae ejus statu transmissae. Impressae Lugduni per Johannem de Vingle. Anno Domini MCCCCC quinto, Die VIII Novembris".

Ik zal nu de belangrïke voorrede dezer uitgave doen kennen. Deze is daarom zoo belangrijk omdat Ambrosius van Milaan daarin bijna geen woorden genoeg kan vinden om de ombekwaamheid en slordigheid van de Duitsche 
drukkers van die dagen aan te vallen; zoodat hij zelfs betwïfelt of de uitrinding der drukkunst wel eene weldaad is voor de wereld.

A mbrosius, archintus patricius Mediolensis, lectori salutem.

Pervenerunt nuper ad manus meas Aenaei Sylvii Picolominii Senensis, viri clarissimi epistolae, quas dum in minoribus ageret, aut nondum cardinalatus dignitatem excessisset ad principes, ad amicos et fautores suos ex tempore dictabat. Eas cum legissem, indolui tanti ingenii vicem, quod vir latinus et eruditissimus, qui nemini patrum nostrorum memoria in omni scientiarum genere cedit, ab horrida Germania corrupte imprimeretur; et non ab re inter litteratos saepe disceptatum est, profueritne humanae societati impressoria haec ars, vel potius obfuerit. Comperi enim ex earum lectione infinitos errores, ut divinandum potius esset quam legendum. - Cogitanti igitur mihi et ipsius Aeneae elegantiam et miram epistolarum ipsarum utilitatem, concinnamque brevitatem risum est quidquid temporis subfurari potui redigere epistolas ad aliquem ordinem, ut omnes intelligant pro virili mea tanto viro me affici, qui propria virtute, et non favore nec fortuna ex humili loco ad fastigium summi pontificatus erectus est. - Is enim a teneris annis litteris deditus, jurique postea Caesareo operam dedit; mox ut intestinas factiones evaderet Mediolanum se conferens praepositura sancti Laurentii maioris Mediolani donatus est. Deinde in Germaniam profectus in concilio Basiliensi, quo tota virornm doctorum summa convenerat, omnium judicio et doctissimus et modestissimus judicatus est, et non immerito dirus Fredericus, tertius Romanorum rex, in secretarium delegit, laureatum poetam reddidit; et post multos exanclatos labores Tergestinensem episcopatum nactus, vacanti deinde ecclesiae Senensi, patriae suae sufficitur. - Demum post longas pactas vigilias pro republica Christiana ad cardinalatus dignitatem a Calixto, pontifice maximo promotus, eidemque morienti, summo omnium favore ad supremum illud dignitatis culmen Aeneas ipse immediate successit. - Non enim prudentia ejus res praeclare gestas enarraturus accedo, quae a viris probatissimis tractatae sunt, ne forte, dum illius laudes referre vellem, ob ingenii mei exiguitatem eas potius labefactarem. Tanta est enim maximi hujus pontificis gloria, ut nullius laude crescat, nullius vituperatione 
minuatur. Otinam is semper vixisset! Qui jacentes litteras sublerabat, et doctos in omnium scientiarum genere praemiis et dignitatibus decorabat, utque ad virtutes omnes alliceret; non quorumdam more, qui, facti roti sui compotes, virtutes prosternunt. - Is, pontifex dignissimus Pius nominatus secundus, quum assiduus obrueretur occupationibus, semper aliquid legebat scribebatque manu sua. Extat et alter volumen egregium, quod in pontificatu maximo ad reges et principes exaravit. Tandem dum bellum contra foedissimam Turcorum gentem pararet, et in anchoris staret classis in Anconae portu divinam animam efflavit, relicto apud omnes Christianos sui desiderio. Quod relictum est, has lecturos epistolas et oro et obsecro, ut, si quid minus accurate impressum extiterit, impressoribus vitio dent, qui datum sibi ordinem persaepe non servant; mihi vero ignoscant, quod impressoribns adesse non possum. Hoe tamen elaborari, ut epistolae, quae apud Barbaros impressae sint, et vix quattuor volumina ad Italos pervenerunt, omnibus essent cum parro aere copia, et meliori artificio impressae, correctioresque et emendatiores haberentur, quia Germania illa Latinorum nominum rocabula ignorat, ordinemque confundit. Teneat itaque barbara Germania codices suas, quia, Ambrosii Archinti et Johannis Vinzalii, viri docti, qui totum opus revisit, beneficio, studiosis et litteratis multa epistolarum ipsarum volumina in medium allata sunt. - Sis felix, candissime lector, et Pii, bonarum litterarum patris indulgentissimi memor! Cujus umbrae dent Superi tenuem et sine pondere terram! Spirantesque crochos et in urna perpetuum ver!

Mediolani quinto Kalendarum Decembris. Anno partus virginis MCCCCXCVI.

Men zal met mij instemmen dat deze voorrede uit het jaar 1496 veel belangrijks bevat, ook geschiedkundige aanwïzingen, b. v. dat Aeneas Sylvius, nog voor hï naar het concilie van Bazel ging, en lang voordat hij de priesterwïding ontving, met de "praepositura" van den heiligen Laurentius te Milaan werd begiftigd, dit zal wel beteekenen met de proostdï van den Heiligen Laurentius. Mijns inziens is bij toen reeds met een Kanunnikschap, waaraan inkomsten verbonden waren, begiftigd. Immers eerst veel later heeft hï de priesterlijke wijding ontrangen. Immers toen hij secretarius en poeta laureatus van Frederik den 
IIIden was schreef hï daarover aan Petrus van Noretum. Die brief is de vijftigste $\operatorname{van}$ de besprokene uitgave, en omdat hij de zielsgesteldheid van Aeneas Sylvius in die dagen teekenachtig weêrgeeft, en zijne wïze van leven ook, geef ik dien brief hier weder. Het opschrift in de besprokene editie is: "Relegat continentiam ad philosophos". Ook karakteristiek! Die brief luidt aldus:

„Eneas Sylvius, poeta, salutem plurimam dicit Petro de Noreto, scriptori apostolico et fratri amantissimo.

Satis ad te superioribus diebus scripsi, tum de mea erga te voluntate, tum de uxore, quam eras ducturus. Nunc addendum nihil est, nisi quod te rogo ut rescribas saccessum rerum, et an adhuc vir fies. Nam si sic est, dabo tibi onus, ut me quoque virum aliquando facias, si quid inveneris meae opinioni conveniens.

Ego non intendo vitam omnem extra Italiam degere, et adhuc cavi ne me sacer ordo involveret. Timeo enim continentiam, quae licet laudanda sit, verbis tamen quam factis probabilior est, et philosophis magis quam poetis conveniens. Quidquid sit, rescribe petitionibus meis, et me tui status scium facito; et considera me non tam mei quam tui boni cupidum esse, et gaudere omni tua fortuna. Postremo investiga omnes vias, si quae inveniri possint, ut aliquo Theutonicus Eneas fat Italicus.

Vale.

Als wij bedenken, dat paus Pius de tweede in 1406 geboren is, en dat wïj wel niet ver van de waarheid zullen zijn, als wï borenstaanden brief in het jaar 1444 of 45 plaatsen, eenigen tijd voor zijne wijding tot subdiaconus, den 6den Maart 1446; dan zien wij hoe de man van 38 of 39 jaar nog met denzelfden wellustigen geest vervuld was, als toen $h \ddot{j}$ in het jaar 1444 zijne vurig erotische novelle: "Euryalus en Lucretia" schreef, en aan zijnen rriend Sozzini toezond.

De Ultramontaansche geschiedschrijver Janssens heeft Pius II wat rein willen wasschen van den vlek van onzedelijkheid. Hij laat van 1444 eene verandering ten goede bij den lateren paus intreden. Hij is voldoende wederlegd. Niet onbelangrïk echter is het, ook ter wederlegging van 
Janssens, den brief te lezen, dien Aeneas Sylvius nog als bisschop van Siena aan den cardinaal Dominicus Firmanus schreef, en te zien hoe hï daarin nog over zich zelven spreekt. In het jaar 1447 werd Eneas tot bisschop van Triest benoemd, en in 1450 werd hij bisschop van Siena. De brief, in de uitgave van Ambrosius CCCCXXVII genummerd, zal wel niet veel later geschreven zijn. Het opschrift van den brief luidt:

"Commendat fratres beati Francisci de observantia".

Aeneas, episcopus Senensis Dominico cardinali Firmano, S. P. D.

Quamvis scribente Caesare, ad negotia fratrum beati Francisci de observantia commendante, modestius fuerit me silere; quia tamen ob memoriam divi Bernardini, conterranei meí, huic familiae singulariter afficior, nequeo me comprimere, cogor assistere sanctae familiae. Neque mea patrocinia his negare possum, qui non me solum, sed omnes Christi fideles suis orationibus ac piis operibus adjutant. Utinam esset in me auxilii copia et aliquid posset patrocinium meum! Profecto nibil his Dei servis denegarem.

Nametsi sum ipse peccator et iniquitate circumdatus, diligotameneos, quorum vitam castam, mundamque video; quia, quanto minus est in me virtutis, tanto eos jurare attentius debeo, quorum probitas in aperto est. Et si nequeam meis actibus Deo placere, horum saltem commendationibus reddar acceptus.

De spatiëering is natuurlijk van mij, en deze brief werd in 1450 of 1451 geschreven. Verder gaat Eneas daarin roort de Franciscanen van de strenge observantie te verdedigen, daar hij vernomen heeft dat Nicolaas de Vde tegen hen opgestookt is. De Franciscani observantes staan bij hem verre boven de Franciscani conventuales, op welke laatste hij nog al wat heeft aan te merken.

$\mathrm{Ja}$, bekend is het, dat de latere Pius II een zeer bewogen leven heeft geleid vóór hij tot paus werd gekozen, en dat hï een man was van zeer zinnelijken aard. De geschiedschrijver B. Platina, die in 1421 werd geboren on 
in 1481 stierf, en die in het jaar 1474 zijne geschiedenis der Pausen schreef, was een groot bewonderaar van Pius II, wiens gebreken en misslagen hij steeds zoekt te verbergen, te bemantelen, of te verontschuldigen; hij zegt van de gedichten door Aeneas Sylvius in zijne jeugd uitgegeven : " praeclara poëmata Latina et Hetrusca lingua odidit, ludens credo in amorem, quo aetas illa maxime conflictatur". Maar het allerduidelijkst blijkt ons wel hoe vurig zinnelijk de aanleg van Aeneas Sylvius was uit den beruchten 15 den brief uit zijne brievenverzameling, die J. C. L. Gieseler in zijn "Lehrbuch der Kirchengeschichte" (DI. II, $4^{\text {de }}$ afdeeling, blz. 260 in de aanteek.) voor een deel aanhaalt. Die brief werd geschreven in het jaar 1443, toen de schrijver dus reeds 37 jaar oud was. Ik zal dien brief hier in zijn geheel uit de door $m \ddot{j}$ besproken editie teruggeven. Ten eerste toch blijkt uit dien brief de gemoedstoestand van den lateren paus op mannelijken leeftijd, en in de tweede plaats kunnen bezitters van de werken van Pius II dan hunnen text met dien van de oude Lyonsche editie vergelïken.

\section{Epistola XV.}

\section{Eneas Sylvius pootagenitorisuo Sylvio salutem.}

Litteris, an doleas quod mihi sobolem Dominus dederit, incertum te scribis, pater. At ego laetitiae causam video, doloris non rideo. Quid enim dulcius in humanis est, quam gignere sui similem, tam quam extendere sanguinem, et habere quem post te relinquas? Quid in terris beatius quam natos videre natorum? Mihi equidem ingens roluptas est, quod semen meum foetificaverit, quodque antequam moriar aliquid de me supersit:gratiasque Domino refero quod partum feminae gigurarerit in marem, ut apud te patrem, meamque matrem aliquis parrus ludat Eneas, et solatia praestet avis, quae debebat pater impendere. - Quod si tibi, genitor, gaudio fuit meus ortus, cur filius meus mibi non sit laetitiae? An ne te quoque laetificabit infantuli vultus, cum meam videbis in illo effigiem? Numquid tibi jucundum erit cum parrulus pendebit ex collo Eneas, puerilesque blanditias agitabit? - Sed ais forte dolere meum 
crimen, quod ex peccato genuerim flium; nescio quam de me tibi finxeris opinionem. Certe nec lapideum nec ferreum genuisti filium, cum esses tu carnens. Scio qualis tu gallus fueris! At nec ego castratus sum, neque ex frigidorum numero. Nec sum hypocrita, ut videri bonus quam esse velim. Fateor ingenue meum erratum, quod nec sanctior sum Daride rege, nec Salamone sapientior. Antiquum et vetus est hoc delictum, nec scio quis hoc careat. Late patet haec pestis, (si pestis est naturalibus uti), quamquam non video cur tantopere damnari coïtus debeat, cum natura, quae nihil perperam operat, omnibus ingenuerit animantibus hanc appetitum, ut genus continueretur humanum. Sed dicis, ut arbitror, certos esse limites, intra quos hoc liceat; nec extra legitimas matrimonii faces progredi debet hic appetitus. Ita est sane; et saepe inter ipsa nuptiarum claustra scelus admittitur. Et bibendi quoque, comedendi et loquendi certi sunt termini, sed quis servat illos? Quis tam justus ut septies in die non cadat. Loquatur hypocrita, seque nullius culpae scium dicat. Ego nullum meritum in me scio, solaque mihi divina pietas spem facit Mariae, quae nos labiles scit et ad lasciviam proclives, nec nobis, qui patet hominibus, fontem veniae claudet".

Ik breek hier even het overschrïven van den brief af, om er op te wijzen, hoe ook in dezen brief het vertrouwen van Eneas Sylvius op Maria als middelaresse sterk uitkomt, evenals in het vers aan den aanvang dezer studie. Eene wonderlijke vereeniging van godsdienstigheid en geloof met eene zeer sterke wellustige zinnelïkheid vinden wij bij dezen begaafden man. Hij oordeelt wel voortdurend zich zelven, en vindt niets goeds in zich zelven, maar daartegenover staat dat hij zijn eigen talenten en gaven zeer hoog stelt, en zich vaak daarop verhoovaardigt. Daarbij is zijne eerzucht en heerschzucht zeer groot; en is hij alles behalve kiesch in de middelen om zijne zelfzuchtige doeleinden to bereiken. Hij wil hier geen nhypocrita" zijn; maar als men de brieven leest, waarmede hij zijn geleidelijken overgang van de partij van het Concilie van Basel tot paus Eugenius tracht to verdedigen en te rechtvaardigen; (b.v. den brief aan Johannes Carvagialla, „orator apostolicus atque jurisconsultus", de 25 ste in mijne uitgave, en vele andere brieven); dan kan men wel niet anders, 
dan den schrijver daarvan slim en listig noemen. Wereldsgezind was Eneas Sylvius ook in zeer hooge mate, steeds op eigen roordeel en bewondering bedacht. En toch, al wilde hï zoo den Mammon dienen, hij had ook behoefte aan geloof, en heeft mijn inziens nooit geheel met eene godsdienstige levensbeschouwing gebroken. Nooit heeft hij gezegd, of zou hï hebben kunnen zeggen, wat men aan een anderen paus toeschrijft: ,iedereen weet hoeveel de fabel van Christus ons gebaat heeft". Toch blijft het zeer waar wat Archibald Bower neêrschrijft in zäne beoordeeling van het karakter van Pius II: "Wanneer de Keizer de onzijdigheid ombelsde, deed hij het ook; wanneer deze zich genegen toonde om Eugenius tegen het Concilie en tegen Felix te begunstigen, verklaarde hij zich openlijk tegen die beiden; en toen hij door Frederik met eөnige voorslagen naar Rome gezonden werd, nam hij die gelegenheid waar, om zijn vorig gedrag te veroordeelen, on Zijne Heiligheid te smeeken hem zulks te vergeven, en in zijn gunst te willen ontrangen". Niet allén aan de zonde van wellust en groote buitensporigheid staat Eneas Sylvius schuldig, maar ook aan die van groote oneerlijkheid en geveinsdheid, en het is dus geen wonder wanneer wij in het vers aan den aanvang dezer studie lezen:

„Ipse ego, peccati servus, scelerisque minister, Et mandatorum fractor ubique decem".

Maar ik ga voort met de copie van den beruchten XVden brief. ${ }_{n}$ Sed de hoc satis. Nunc, quod conjecturas petis ne alienum pro meo nutrias, quomodo res se habuerit paucis exponam. Nondum anni duo effluxerunt ex eo tempore, quo Argentinae gerebam oratoris munus. Quinquagesima tunc currebat, quae ante primam praeteritam fluxit. Hic, cum otiosus essem diebus pluribus, mulier ex Brittania veniens diversorium meum petens in unis aedibus mecum fuit, non invenusta, nec aetate confecta. Haec, quae sermonem Italicum egregie noverat, me verbis salutabat Etruscis; quod illa in regione tanto magis placuit, quanto rarius erat. - Oblectatus sum facetiis feminae, cujus in ore maximus lepor erat. Moxque in mentem renit Cleopatrae facundia, quae non solum Antonium, sed Julium quoque Caesarem elo- 
quentia inescavit. - Mecumque quis reprehendet, inquam, si ego, homuncio, faciam quod maximi viri non sunt aspernati. Interdum Moysen, interdum Aristotelem, nonnunquam Christianos in exemplum sumebam. Quid plura? Vicit cupido, incalui, malierem arsi, multisque blandimentis adorsus sum. Sed ut asperis cautibus unda repellitur freti, sic verba mea contempsit, triduoque suspendit. Erat illi filiola annorum quinque, quam ex militibus pater hospiti nostro commendaverat, verebaturque mulier, ne quid hospes persentiret, filiamque posthac, quasi moris materni, abdicaret. - Instabat nox; sequentique die mulier recessura erat. Timeo ne abeat praeda. Rogo in noctem ne ostio camerae pessulum obdat. Dico me intempesta nocte venturum. Negat, nec spem ullam facit. Insto semper. Idem responsum est. Itur dormitum. Mecum ego: quid scio an illa ut jussi fecerit. Recordor Zimae Florentini. Forsitan illius amicam haec imitabitur. Tentandum est, inquam. Postquam silentium undique sentio thalamum mulieris accedo. Clausum ostium est, sed non obfirmatum. Aperio, ingredior, muliere potior. - Hinc natus est filius. Mulier Elisabeth vocatur. Ex Idibus Februarii, usque ad alias Idus Novembris menses currunt qui partui dantur. Haec mihi dixerat mulier, dum Basileae postea erat. Ego, quamris ipsam non pecunia ulla, sed maximis emissem precibus, (ut est ars feminarum), credebam haec auri corrogandi causa dici, nec verbis praebui fidem. Nunc, quod eam hoc asserere, qua nibil imperare a me potest, qua nomen convenit tempusque, puerum meum puto; teque, mi pater, rogo ut nepotem suscipias, alasque, donec, grandiusculus factus ad me valeat proficisci ; meisque imbui disciplinis. Nec puta feminam divitem mentiri velle in filio. - Nune alia prosequar. Scribis te senio cum matre confectum.

Hoc, mi pater, tibi sibique jucundum esse debet, quod eos annos attigisti quos optabas jurenis, jamque libere et expedite potes Deo servire, omnibus spoliatus possessionibus, quae mentes jurenum a Deo alienant. Nec mihi dixeris omnia fert aetas animumque, ut ex hoc animum perire putes, qui divinus est atque immortalis; sed voluit significare aetatis cursu vigorem illum animi tepescere, qui est juvenibus ardens. Sed ille magis ad vitia quam ad virtutes inclinat. In senibus purgatus est animus, nihil praeter honestum cupiens, qualem tibi et matri meae spero esse; quamris illa nunquam mundanis desideriis inhaeserit, sed heroĩca quadam virtute solum Deo servire beatum 
direrit. Hoc fit ut senio vestro minus trister. Si enim jurenes essetis timerem de vobis magis. - Quod de filiis sororis Landomiae scribis certum est apud me gratumque. Tuum est curare ut litteras discant, quae solae homines extollunt super alios. Ego, cum statum meum firmiorem videro, alterum mihi asciscam. Jacobus Ptolomaeus frater si ad me scripserit responso non carebit; provocari litteris non expectet. Toties enim necessario scribo, ut nihil ad libitum vacet. Lectura ejus ordinaria salarioque laetatus sum, famamque suam in dies crescere cum laetitia percipio. - Bartholomeo cum presentibus litteras do, nec ejus obliviscor unquam, pro suis erga te matremque meritis, et quod Catherinam, matris meae sororem, conjugem suam, unice amat. Matremqus tibi commendo, tuaeque fidei, Deumque rogo ut patriam petens superstites omnes inveniam. Conventum namque cum laetitia celebrabimus. Et quoniam id quod restat viramus spatium ex tuo transigemus arbitrio, nec mihi in te ulla erit controversia.

Johannem et Landomiam uxorem jube ex me salvos esse.

Filiolum suscipe, et quidquid egeris mihi rescribe.

Vale.

Zeker uit dezen brief blijkt ons, vooral ook door de wïze, waarop hij zijn vader aanspreekt, en door de levendige, zeer plastische beschrïving van zijn eigen wellustig bedrïf, zoowel Aeneas Sylvius buitensporige zinnelijkheid, als zijne groote onbeschaamheid. Toch vindt men bij dezen zelfzuchtige eene zekere goedhartige belangstelling in en toegenegenheid voor zijne familiebetrekkingen. Eene zekere goedhartigheid doet zich vaak voor bij de zinnelijke naturen. $\mathrm{Z}_{\mathrm{ij}}$ gunnen ook anderen wel iets goeds, en willen daartoe ook wel een weinig medewerken; maar het moet han geen te zwaren strijd, en geen belangrïke opofferingen kosten. Vooral als zij in welstand on voorspoed verkeeren, als zij zich op hunne wijze wel voelen, betoonen zij zich in den omgang wel eens goedhartig, zoodat men soms wel eens aan hunne zelfzuchtigheid zou kunnen twijfelen, als men opmerkt dat soms hun gevoel voor anderen zich op welwillende wijze uitspreekt in hunne woorden, ja zelfs in hunne daden. Vooral Eneas' bewondering voor de welgemeende vroombeid zïner moeder is klaarblïkelijk oprecht 
in onzen brief bij onzen zeker vaak onoprechten schrïver.

Wie toch kan gelooven dat hij, die als Aeneas Sylvius de rechten van een algemeen concilie, en dus ook van het Bazelsche, had verdedigd, aan zulk een concilie hoogere macht dan aan den paus had toegekend; dat deze man, die ook de geschiedenis van den Roomschen stoel in vroegere eeuwen zoo door en door kende, werkel ijk een overtuigd voorstander van de allergrootste uitbreiding van de pauselijke macht is geworden? Terecht schreef $R$. Zoepffel in Herzog's Real-Encyclopedie, over de verandering van Aeneas Sylvius, die het machtigst uitkwam, toen hij als Pius II op den pauselijken stoel was gezeteld: „Mit dieser Bulle "Execrabilis" hat Pius $\Pi$ zugleich jedes Streben nach einer Kirchenreform zu ersticken gesucht, obwohl er als Glied des Baseler Konzils die Reformbedürftigkeit der Kirche besser als irgend ein Römischer Prälat kannte. Der radicale Bruch Pius' II. mit seiner Vergangenheit bewiese allerdings eine dem Papalsystems innewohnende unwiderstehliche Macht, wenn man annehmen könnte, dass Aeneas Sylvius einst aus reinster Begeisterung sich zum vorwarts drängenden Verfechter der Ansprüche des Baseler Konzils aufgeworfen hätte. War aber, wie man zu behaupten allen Grund hat, die Triebfeder seines Redens, Schreibens und Handelns zur Zeit des Baselschen Konzils, and auch nachher, die Maxime, unter jeder Flagge zu segeln, die ihm Gewinn und Ehren in Aussicht stellte, so erscheint dieser Abfall Pius $\Pi$, von den Theorien des Aeneas Sylvius als das Schlussglied in der grossen Kette von Gewissenlosigkeiten eines an keine festen Grundsätze gebundenen, nur dem Augenblicke und dem Nutzen Rechnung tragenden Schmeichlers sowie Spielballes der jeweiligen Zeitströmung". Niet te rergeefs heeft Pius II zoo gevreesd dat de latere geschiedschrijver de woorden en geschriften van Aneas Sylvius tegenover zïne latere bullen, rescripten en handelingen zou stellen.

$\mathrm{Na}$ de bul: „Execrabilis et pristinis temporibus inauditus", etc. den 23 Januari 1460 uitgevaardigd, volgde den 26sten April 1463 de bulla Retractationum, waarin hij van 
vele zijner vroegere geschriften zegt: „Utinam latuissent quae sunt edita". Hï getuigt van zichzelren: „ambularimus in tenebris, et procul a vera luce recessimus: nec nobis tantum erravimus, alios quoque in praecipitium traximus, et caecis ducatum praebentes, caeci cum illis in foveam recidimus". Hij roept uit: „seni magis quam juveni credite, nec privatum hominem pluris facite quam Pontificem: Aeneam rejicite, Pium recipite". Maar al dat pauselijk gebazuin en getrompetter heeft hem niet geholpen. Oordeelkundige geschiedschrijvers hebben steeds gezegd: Pius II heeft in zijn loopbaan zijn eigen voordeel steeds in het oog gehouden, als paus heeft hï zich door zijn heerschzucht voort laten drijven. Ik geloof dat men zelfs niet zeggen kan: dat paus Pius zich door zijne heerschzucht beeft laten verblinden.

Als men niet wist hoeveel kuiperijen van wereldlijke zoowel als van geestelijke zijde er soms bij de verkiezingen van pausen zijn voorgevallen; dan zou men kunnen vragen: hoe heeft men hem ooit tot paus kunnen verkiezen ? Zijn erkende werkijver en zijne groote talenten waren zeker niet te loochenen; maar eene zedelijke persoonlijklïkheid was bij zeker niet; en naar zulk eene persoonlijkheid moeten orertuigd Roomsch-Katholieken bij zulk eene keuze toch wel allereerst vragen.

Kan men dan niet van eene bekeering, van een zich toewenden tot het goede spreken bij paus Pius? Ik geloof dat het door mij aan het begin dezer studie open- baar gemaakte vers daarvan spreekt. Zulk eene verandering ten goede is bij hem begonnen, toen hij in 1446 in een zijner brieven neêrschreef: „hï is wel een ellendig mensch, en hem is niets van goddelijke genade ten deel gevallen, die niet eindelijk tot zijn beter ik terugkeert, in zichzelven inkeert en zijn wandel betert, die er niet over nadenkt, wat, na deze wereld in eene andere zich zal voordoen. Ik heb genoeg en overgenoeg verkeerds gedaan, reeds keer ik tot mij zelven in, o! mocht het niet to laat zijn"! Wel lezen wï eenige regels verder (want hij wist aan wien hï schreef): „Doch wat kan deze ernst tusschen u en mij 
helpen? Ik weet dat ik tevergeefs spreek, dat gij mij niet vertrouwt. Gij denkt dat ik met een volle maag het vasten aanraad. Ik beken het $u$, liefste broeder, ik ben vol, ik heb or genoeg ran, ik heb het tot walging van Venus gebracht." Wel zegt de geleerde Zoepffel, na het aanhalen dezer woorden: "Dass der tiefste Grund der Abkehr des Piccolomini von den sinnlichen Ausschweifungen nicht Büsse und Reue ueber dieselben, sondern körperliches Siechtum war, beweist die hier von ihm abgegebene Erklärung das seine Sehnen so matt, seine Knochen so morsch seien, dass er keinem Weibe mehr zur Lust dienen, und ihm kein Weib mehr Lust bringen konne"; wel haalt hij den uitroep aan: „Beim Hercules, an der Keuschheit hab ik wenig Verdienst; denn lasse mir die Warheit sagen, die Venus flieht mich mehr, als ich Sie verabschene". Daarop volgt echter zou ik zeggen: „Doch ich danke Gott, dass das Begehren nicht grösser ist als das Können". Die zin althans spreelst in zijn eenroud van een begin van iets beters in Aeneas Sylvius, in den strijd tegen zijne hoofdzonde. Ook lichamelijke ellende kan naar iets beters doen tasten en zoeken dan naar zinnelijk genot; zij kan een der middelen zïn, waardoor God van de zonde doet terugschrikken. Dat gelooven toch alle Christenen. Er is iets in dien brief van ware rriendschap, die den vriend, aan wien hij gericht is, ook tot eene meer ernstige lerensbeschouwing wil stemmen; al weet hij, dat hij aan een vroegeren "socius peccatorum" schrijft.

0 zeker, Aeneas Sylvius was met dat begin van inkeeren in zichzelven nog niet tot eene Christelijke gemoedsgesteldheid gekomen! Altijd is er nog iets van den humanist in hem blijren leven. De wereld had hij nog waarlijk niet opgegeven. Ook toen hij in 1456 tot Kardinaal was benoemd door paus Calixtus den IIIden, en voortaan in Rome verblijf hield, had Aeneas steeds vertrouweln̈ken omgang met Rodrigo Borgia, het zedelijk monster, dat als paus Alexander VI nog meer zajn waren aard zou toonen, dan hij het reeds als kardinaal gedaan had. Met dezen man, die later veel heeft medegewerkt om Aeneas tot paus te doen VII. 
verkiezen, jaagde hï er naar om begiftigd te worden met allerlei prebenden en kerkelijke inkomsten. Zulke prebenden trok hij zelfs uit de provinciën Mainz, Trier en Keulen tot een bedrag van 2000 dukaten. Niet dat hij den rijkdom op zich zelf lief had. Het geld was hem een middel om macht te verkrijgen, en om aan zijne litteraire en artistieke behoeften te voldoen: want voor zich zelf leefde hij in dien tijd en later zeer matig. De uitgaven voor zijne huishouding als paus bedroegen slechts van zes tot acht dukaten dagelïks, maar hï gaf aanmerkelijke sommen uit voor het opzoeken en afschrïren van Latïnsche en Grieksche Codices, zooals bewezen is door de rekeningen van de pauselijke schatkist. De liefde voor de letteren bleef steeds leven in het hart van den ouden humanist.

Maar niettegenstaande dit alles meen ik te mogen zeggen, dat eene verandering ten goede in de laatste jaren van paus Pius II zeker valt waar te nemen. Steeds was het in zijn gemoed eene wonderbare vermenging van humanisme, geloof en bïgeloof geweest. Dat geloof was aanvankelijk meer van intellectueelen aard; een rationalistisch voor - waar houden, dat nog geen grooten invloed kon oefenen op zijn leven. Meer invloed op zijn gemoed begonnen die geloofsgedachten te oefenen, toen zijne zinnelijke natuur ten gevolge zijner lichamelïke verzwakking daaraan minder in den weg stond. De gedachte aan de rroomheid züner moeder, die naar wij uit zijne brieven zagen ook vroeger grooten indruk op hem gemaakt had, heeft misschien ook medegewerkt ten goede; en dan zou op hem in mindere mate toepasselijk zijn wat Ambrosius als troostwoord tot Augustinus' moeder richtte: "een zoon van zooveel tranen en gebeden kan niet verloren gaan". Ik geloof niet dat al de ernst, dien Pius in zijn latere jaren deed blïken, gehuicheld was.

Van zijn j̈ver om de volken van Europa tot een kruistocht tegen de Turken, die in die dagen alles dreigden te overweldigen, op te wekken, zou ik niet willen zeggen, wat men wel eens gezegd heeft, „dat hij met den vurigen jiver van een Italiaansch Humanist het voorportaal van 
de Grieksche beschaving niet in de handen van Barbaren wilde laten". Neen, de Pius, die nooit een ongeloovige was, heeft in zijn laatste tien levensjaren, zoowel onder het pausschap $\operatorname{van}$ Nicolaas $\nabla$, als onder dat van Calixtus den IIIde, steeds op een kruistocht tegen de Turken aangedrongen. Er moge daar iets van politiek, iets van humanistische liefde voor het codices bewarende Konstantinopel b̈̈gekomen zïn; zeker was zijn hart in die dagen niet koud voor de belangen van godsdienst en Christendom, zooals hij die opvatte en bevorderen wilde. Daarvan getuigt ook zijn uitroerige brief aan Mohammed II, die moest strekken om dien vorst tot het Christendom te bekeeren. Wat hem hiertoe bracht was zeker het in die dagen zich verspreidende gerucht, dat Mohammed II eigenlijk geen rechtzinnig Mohammedaan was. Dit is misschien wel waar geweest, daar deze sultan een groote, krachtige geest was, die zich moeilijk geheel aan de leiding zjjner bekrompen geestelijken heeft kunnen onderwerpen. Dát kan bij Pius de hoop op mogelïk goed gevolg gewekt hebben, toen hij in dien brief aan Mohammed eene uitroerige ontwikkeling gaf van de grondleeringen en de gevoelens, die in de Roomsche Kerk heerschende waren, met de vermaning daarbij, dat hij als een nieuwe Constantïn de Groote tot het Christendom zou overtreden, en de belofte, dat de paus hem dan als Keizer over het Oosten en over Griekenland zou erkennen.

$\mathrm{Du}$ Plessis Mornay heeft zich zeer aan den brief des pausen geërgerd, (zie diens "Mystère d'iniquite", pag. 542), maar de eerlijke Archibald Bower zegt in zijne geschiedenis van de pausen: "dat hij er niets in vinden kon, dat een Christen of bisschop onwaardig zou zün". En dat is waarheid. Een paus, die zich gevoelde als een, die geroepen was om het hoofd der Christenheid te zijn, mocht, ja moest in die benauwde dagen zoo schrijven. Die brief mag, zooals vele andere brieven van Pius, iets hoog-oratorisch, gekunstelds en opgesierds hebben, zooals van een humanistisch gevormde in die dagen te verwachten was; hij is m. i. een getuigenis, dat Pius zich in vollen ernst 
wijdde aan de taak van "pastor orbis terrarum", waartoe hij zich in zijne meer ernstige latere jaren geroepen achtte. In den brief komt niet alleen eerzucht en grootheidswaan aan het woord; neen er straalt ook ware belangstelling in het welz̈̈n der Christenheid in door, zooals Pius dat opratte in die dagen, gelijk blijkt uit het vers, dat mij aanleiding gaf tot deze studie; en met zijne veroordeeling van zijn vroeger leven, dat hij met smarte herdacht, was hij ook gekomen tot eene veroordeeling van zijn vroeger denken en streven. Het is toch wel te begrijpen, dat de nu verouderde man, bï den zoo verwarden toestand van de Kerk in Frankrijk, (men denke aan de bewegingen over de Pragmatieke Sanctie), en in Duitschland óók, (ik noem slechts de namen van Diether van Isemburg, Sigmund, hertog van Tirol, George Podiebrad, Koning van Bohemen, en Gregorius van Heimburg), een meer énhoofdig en monarchaal-despotisch bestuur der Kerk wenschelijk, ja voor het oogenblik ten minste onontbeerlijk achtte.

Dat Pius het in zijne laatste dagen goed meende blijkt wel vooral uit de rederoering, die hij tot de Kardinalen heeft gehouden, toen hij zich bereid verklaarde zelf mede ten kruistocht tegen de Turken te trekken. Met een lichaam vol jicht, in die mate, dat hij van den gordel af balf verlamd was, besloot hij in persoon mede den aanval te doen op het machtige Turksche rijk, om daardoor vernieuwde geestdrift te wekken voor het zoo noodige werk $\nabla a n$ het terugdringen der overweldigende Turken. Hij had toen reeds Frederik III en Mathias Corvinus weten te verzoenen, opdat zij zouden kunnen samenwerken tot den kruistocht, Philips van Bourgondië had hem plechtige geloften gedaan om ook zijn machtigen steun te verleenen. Door allerlei omstandigheden - Lodelijk XI van Frankrijk hield den Bourgondiër terug om zijne geloften getrouw te vervullen, werd de paus op het laatste oogenblik teleurgesteld. Alleen Matthias Corvinus, Venetië en de paus zelf bleven als werkdadige bondgenooten over. Toch wil Pius doorzetten. In zijne rede tot de verzamelde kardinalen kondigt hij zijn vast genomen besluit aan om zelf ten kruistocht te trekken, 
en hï wekt hen op daaraan ook deel te nemen. Aandoenlïk zijn de navolgende woorden uit die redevoering: „Sterven moeten wij toch eens.... Zalig, die sterven in gehoorzaamheid aan den Heer. Een goede dood verzoent een verkeerd leven. Wij meenen dat het wel met ons is, wanneer het Gode zou behagen, dat wij in Zijnen dienst onze dagen eindigden".

"Een goede dood verzoent een verkeerd leven". Ook in die woorden spreekt het geweten. Slechts 58 jaar, 9 maanden en 27 dagen is Pius als een verzwakt grijsaard gestorven; en hij heeft het geroeld in zijne laatste dagen, dat hij zelf schuld had aan zijn vroeg verouden. Toch ging hï 19 Juni 1464 op reis naar Ancona om zich ten kruistocht in to schepen, en den 15den Augustus stierf hij, nadat hij nog op den $12^{\text {den }}$ dier maand de Venetiaansche vloot op de reede $\operatorname{ran}$ Ancona had zien aankomen.

De aangehaalde woorden uit de rede tot de Kardinalen "Een goede dood verzoent een verkeerd leven" spreken van dezelfde wroeging en van hetzelfde berouw, dat Pius in zijn $z$ wanenzang de belijdenis ingaf:

„Fateor, mortalia septem

Saepius admisi crimina ;... nunc poenitet".

Pius' zwanenzang zegt ons, dat zelfs een leven als dat van dien paus het hoogere in den mensch niet geheel vernietigen kan; en dat een menschenhart, ook na een leven in zeer ergerlijke zonde, kan blijven hongeren en dorsten naar betere dingen dan aardsche en zinnelijke genietingen.

Groningen. 